\title{
The 14th International Conference of the International Society for Scientometrics and Informetrics
}

\author{
Juan Gorraiz • Christian Gumpenberger • Marianne Hörlesberger • \\ Henk Moed • Edgar Schiebel
}

Received: 25 August 2014/Published online: 23 September 2014

(c) Akadémiai Kiadó, Budapest, Hungary 2014

The International Conference of the International Society for Scientometrics and Informetrics (ISSI) is certainly amongst the world's largest and most prestigious of its kind in our field.

The last event, the 14th ISSI conference took place at the University of Vienna 15-19 July 2013 and was jointly organised by the University of Vienna and the AIT Austrian Institute of Technology.

It will certainly be remembered as one of the biggest and most successful ISSI conferences since its foundation. The large number of 389 participants from all over the world exceeded all expectations from the organisers by far. The countries with the highest number of participants were Austria (host), Germany, China, Spain and the United States.

The large number of submissions (338) by more than 900 authors affiliated to organisations located in 42 countries reflects the large interest sparked internationally. The top three contributing countries were China (149), Spain (129) and the USA (101). All contributions were reviewed by the International and Local Committees. Thereof 145 (107 full papers and 38 research in progress papers) could be accepted for oral presentations.

After the conference, authors of oral presentations were invited to submit an essentially extended version for possible publication in a special issue of Scientometrics. All papers have been reviewed anew, and on the basis of this process 38 papers have finally been selected.

J. Gorraiz $(\bowtie) \cdot$ C. Gumpenberger

Library and Archive Services, Bibliometrics Department, University of Vienna, Boltzmanngasse 5, 1090 Vienna, Austria

e-mail: juan.gorraiz@univie.ac.at

M. Hörlesberger · E. Schiebel

AIT Austrian Institute of Technology GmbH, Tech Gate Vienna, Donau-City-Straße 1, 1220 Vienna, Austria

H. Moed

Elsevier B.V., Radarweg 29, 1043 NX Amsterdam, The Netherlands 
The most relevant issues addressed at the conference, like the advent of new metrics (usage metrics and altmetrics) complementary to the classical citation metrics, opportunities and limitations of new (open) data sources for bibliometric purposes, assessing research impact in the social sciences and humanities, obliteration and citation context, the challenges of individual evaluation, collaboration as a motor of productivity, mapping science and network analysis, patents, and university rankings and science policy, are all represented in this issue.

Like the fragrance of a captivating perfume is only defined by its carefully selected essential oils and aroma compounds, the appeal of this special issue also relies on the careful assortment of papers representing the broad spectrum of present-day scientometrics.

The following event of this conference series will be organised in the coming year. The 15th International Conference of the International Society for Scientometrics and Informetrics will be held in Istanbul, Turkey, in summer 2015, 29 June-04 July. 